The natural radioactivity

\section{of the Carpathian national parks and radon evaluation}

Volodymyr T. Maslyuk, Olesya I. Symkanich, Natalya I. Svatyuk, Oleg O. Parlag, Sergij M. Sukharev

\begin{abstract}
The results of the low-background gamma spectrometric measurements of protected mountain areas (Zacharovanyy Kray, Chorne Bahno, Ihthyological Preserve Rika and Uzhanskij National Natural Park) in the region of Primeval Beech Forests of the Transcarpathia, Ukraine, are presented. The distances between sampling points in a single protected area were in the range of $200-400 \mathrm{~m}$ in elevation of $300 \mathrm{~m}$; probes were taken from the surface, from depth $20 \mathrm{~cm}$ and more than $50 \mathrm{~cm}$. The proposed sampling scheme allows one to investigate the radionuclide concentration in protected area's soils, their distribution on/near the mountain ridges and migration in depth $(0-50 \mathrm{~cm})$. We also investigate the influence the soils' $\mathrm{pH}$ on the contents and the migration of nuclides. The obtained data allow us to study the statistical regularities between the sampling points along and down mountain ridges on the base of their radionuclide content. These results are important for evaluating the radon content/distribution and developing standards in the radionuclide content of the soil Carpathian region.
\end{abstract}

Key words: Carpathians $\bullet$ radionuclides $\bullet$ soils $\bullet$ depth content $\bullet$ radon

V. T. Maslyuk ${ }^{\bowtie}$, N. I. Svatyuk, O. O. Parlag

Department of Photonuclear Processes,

Institute of Electron Physics of the National Academy of Sciences of Ukraine,

21 Universitetska Str., 88017, Uzhhorod, Ukraine,

Tel.: +38 (0312) 643524, Tel./Fax: +38 (312) 643650,

E-mail: nuclear@iep.org.ua,

volodymyr.maslyuk@gmail.com

O. I. Symkanich, S. M. Sukharev

Department of Environment Ecology,

Uzhhorod National University,

Pidhirna 46, 88000, Uzhhorod, Ukraine

Received: 5 February 2016

Accepted: 31 March 2016

\section{Introduction}

The Carpathian Mountains are an important source for clean water and clean air for East and Central Europe. It is a powerful factor of climate creation and water regulation on the continent. For this reason, Transcarpathia is one of the leading regions in Ukraine with high 'percentage of reserved lands' $(13.4 \%)$. One should take into account that the mountain ridges are natural air filters that accumulate products of human activities transferred by the wind from the areas with developed industry $[1$, $2]$. The chemical and microelement composition of mountain soils and water resources are formed under the influence of geochemical factors and human activities [3-5]. Further mountain self-purification arises during the rainfall or flood periods and realizes the cyclic exchange of technogenic products between high- and low-land areas [6, 7]. This explains an importance of radioecological monitoring the environment of mountain areas. This also requires studying the features of migration and accumulation of heavy metals and radionuclides for high- and low-land mountain areas and the role of physicochemical parameters of soils and sediments. The mountain protected areas that are almost unaffected by anthropogenic factors are the ideal object of such studies.

The results of radioecological monitoring and mapping the natural radioactivity in high- and 
low-land mountain areas also are important for the elaboration of new methods for the estimation of the concentration of near-surface radon that is a perspective task for Transcarpathia. An actuality of such studies is undoubted, because in Transcarpathia are located many thermal water sources, than may cause some anomalies in radon distribution in the region. Nevertheless, no systematical investigations and mapping the radon distribution in the high- and low-land mountain areas were carried out before.

In this paper, the results of studies of natural radioactivity, its mapping in protected areas of Transcarpathia, obtained on the base of soil probes, are presented. It is shown that the obtained results can be also for the evaluation of the radon distribution in the region.

\section{Radiation mapping of environment and evaluation of radon content}

It is known that radon is one of the elements of the ${ }^{238} \mathrm{U}$ (isotope ${ }^{222} \mathrm{Rn}$ ) and ${ }^{232} \mathrm{Th}\left({ }^{220} \mathrm{Rn}\right)$ radioactive series:

$$
\begin{aligned}
& { }^{226} \mathrm{Ra} \stackrel{-1.6 \mathrm{yr}}{\alpha}{ }^{222} \mathrm{Rn} \stackrel{\text { 3.8day }}{\longrightarrow}{ }^{218} \mathrm{Po} \stackrel{3.1 \mathrm{~min}}{\longrightarrow} \\
& { }^{214} \mathrm{~Pb} \underset{\beta^{-}}{\stackrel{26.8 \min }{\longrightarrow}}{ }^{214} \mathrm{Bi} \stackrel{20.0 \min }{\longrightarrow} \\
& { }^{224} \mathrm{Ra} \underset{\alpha}{\stackrel{3.6 \text { day }}{\longrightarrow}}{ }^{220} \mathrm{Rn} \underset{\alpha}{\stackrel{55 \mathrm{~s}}{\longrightarrow}}{ }^{216} \mathrm{Po} \underset{\alpha}{\stackrel{0.14 \mathrm{~s}}{\longrightarrow}} \\
& { }^{212} \mathrm{~Pb} \underset{\beta^{-}}{\stackrel{10.6 \mathrm{~h}}{\longrightarrow}}{ }^{214} \mathrm{Bi} \stackrel{61 \mathrm{~min}}{\longrightarrow}
\end{aligned}
$$

which are located as in the surface layer, as in deeper horizons of Earth. Radon is a radioactive colourless gas that is heavier than air in 7.5 times, so why it is accumulated near the ground surface, filling lowlands and basements. As it is seen from Eq. (1), ${ }^{222} \mathrm{Rn}$ isotope is more long-living with a half-life $T_{1 / 2}=3.82$ days, as compared with ${ }^{220} \mathrm{Rn}$, which has $T_{1 / 2}=55 \mathrm{~s}$, therefore a biological action of ${ }^{222} \mathrm{Rn}$ in fact is determined by its product ${ }^{218} \mathrm{Po}$.

One can distinguish two channels of the infiltration of radon into the atmosphere: in the results of emanation from the surface layers of the ground, and through exhalation due to diffusion from the deeper horizons of Earth where it appears as a consequence of nuclear reactions. The ratios of the $\mathrm{Rn}$ components (isotopes) that get into the atmosphere due to emanation or exhalation are different, and are determined for a certain territory by characteristics of the soils or rocks. The same characteristics determine also the ratio of the ${ }^{222} \mathrm{Rn}$ and ${ }^{220} \mathrm{Rn}$ amounts in radon gas near-ground atmosphere.

Radioactive mapping of the environment, which is carried out on the base of monitoring of the structure of the natural radioactivity, allows to investigate a content and distribution of the natural and artificial radionuclides in soils, rocks or sediments. Partially, this permits to establish a spread of the isotopes of $U$ and $T h$ radioactive series, which influence substantially on the emanation of radon from the ground surface. Besides territories that are located near Crustal Faults, where the exhalation of the underground radon is intensive, an estimation of the radon concentration in the near-ground atmosphere can be done by using the special sets of the isotopes which are natural markers of the $\mathrm{U}$ and $\mathrm{Th}$ series. Being heavier than air and rather unmovable, radon gas in most cases has concentration which is defined by an equilibrium condition with the amount of isotopes of the mentioned radioactive series that are contained in a near-surface layer of the Earth. As seen from Eq. (1), there are the ${ }^{214} \mathrm{~Pb}$ and ${ }^{214} \mathrm{Bi}$ isotopes as a marker of the radionuclides of the $\mathrm{U}$ radioactive series (for $\mathrm{Th}^{-212} \mathrm{~Pb}$ and ${ }^{212} \mathrm{Bi}$, correspondingly), which can be identified soil samples rather easily using low-background gamma spectroscopy methods (see [8]). Therefore, mapping of radioactivity is a perspective method for the evaluation of the near-surface radon concentration.

\section{The sampling and measuring procedures}

From the studies of the natural radioactivity, the soil probes were taken from four protected areas: regional landscape park 'Zacharovanyy Kray' (Enchanted Land) that ranked to National Park (NP), hydrologic nature reserve - Chorne Bahno (Black Mud), Ichthyological Preserve 'Rika' and Uzhanskij NP. The presence and ratio of certain chemical elements, their markers - natural and man-made radionuclides, could be an important source of information about specific geochemical areas of the Carpathians and their dependence on the technogenic activity in the region $[9,10]$. As mentioned above, the results of such studies are also important for developing the methods and for estimations the radon content of the base of mapping the radiation distribution in the Carpathian area.

With an aim to investigate the peculiarities accumulations and distribution of isotopes of the $\mathrm{U}$ and $\mathrm{Th}$ radioactive series in protected areas of Transcarpathian region and to study the radon dissemination, the special scheme of the soil sampling had been developed. Five-seven sampling points for each conservancy were situated on the mountain ridges, slopes and valleys of the Carpathian Mountains. The distances between the sampling points in a single protected area were $200-400 \mathrm{~m}$ and the total change of the altitude was $300 \mathrm{~m}$. Each sample point was determined by GPS-coordinates. Protected areas are located at the distance of $300 \mathrm{~km}$ from each other and are differed by soil composition and forest ranges. Soil sampling was carried out at the depths of $0-20 \mathrm{~cm}$ (top layer), $20-50 \mathrm{~cm}$ (middle layer), $>50 \mathrm{~cm}$ (bottom layer).

The 'rule of envelope' had been used for the integrated soil sample forming by four sampling points equidistant from the 'envelope' centre. Around each of several samples no less than 4-5 test pits had been carried out and the integrated sample reflects $100-200 \mathrm{~m}^{2}$ area.

The soil samples had been purified from organic substances, dried at room temperature and then sifted. Earthly matter with fractions $<1.0 \mathrm{~mm}$ had been analysed. The soils samples were stored in airtight plastic containers and sealed in a plastic foil 
to prevent cross contamination. The samples were kept for at least 3 weeks before counting to achieve the balance between long-lived isotopes and their short-lived products.

Radionuclide identification was made by the gamma-spectroscopy technique, where the cooled $175 \mathrm{~cm}^{3}$ HPGe and $100 \mathrm{~cm}^{3} \mathrm{Ge}<\mathrm{Li}>$ detectors, the multichannel amplitude analysers and the low-background laboratory had been used. The low-background measurements were carried out in the shielded environment that reduces external gamma radiation in 100 times. In order to reduce the gamma-ray background, the detector was shielded with copper $(8 \mathrm{~mm})$, cadmium $(1 \mathrm{~mm})$, aluminium $(3 \mathrm{~mm})$ and a lead $(95 \mathrm{~mm})$ layers. Conditions for the gamma-spectrometric measurements, such as channel drift and spectrum resolution, were controlled during the investigations, along with stabilization of the low-background conditions of the measurements (moisture content, air convection, etc.). The series of measurements verifying low-background levels were performed periodically (from 4 to 30 hours) and showed its stability. The optimal measurement time should be compared with background conditions and their possible fluctuations to guarantee adequate statistical data processing and accuracy. This verification was carried out in a range (5-50) $\times 10^{3} \mathrm{~s}$ for soils' natural gamma-activity counting. The measuring time of $5000 \mathrm{~s}$ allows accurate testing the soil samples.

For radiation mapping of territory, radionuclides from the $\mathrm{U}$ and $\mathrm{Th}$ radioactive series, as well as ${ }^{40} \mathrm{~K}$, could be used as markers for natural or geochemical characteristics of the area and only if the secular equilibrium of their activities is achieved or almost achieved $[8,11]$. The activity of ${ }^{40} \mathrm{~K}$ natural marker was determined by detection of its single gamma-ray line $-1460.8 \mathrm{keV}$. The intensity of technogenic factors was analysed by the investigation of the ${ }^{137} \mathrm{Cs}$ isotope content in soil probes. ${ }^{137} \mathrm{Cs}$ originated from the atmospheric deposition and its properties make it unique as a tracer for studying the soils erosion and sedimentation.

As mentioned above, the gamma-ray lines of ${ }^{214} \mathrm{Bi}$ $(609.3 \mathrm{keV}$ and $1120.3 \mathrm{keV})$ and ${ }^{214} \mathrm{~Pb}(295.2 \mathrm{keV}$ and $351.9 \mathrm{keV}$ ) can be used to determine the activity of the isotopes of $U$ radioactive series. For Th series, we obtained an equivalent Th content from the detection of ${ }^{212} \mathrm{~Pb}(238.6 \mathrm{keV}),{ }^{212} \mathrm{Bi}(727.3 \mathrm{keV})$ and ${ }^{228} \mathrm{Ac}(338.3 \mathrm{keV}$ and $911.2 \mathrm{keV})$. As a test for radiation equilibrium in $\mathrm{U} / \mathrm{Th}$ series one can use in situ to control the permanency of activity concentration ratio for ${ }^{214} \mathrm{Bi} /{ }^{14} \mathrm{~Pb},{ }^{212} \mathrm{~Pb} /{ }^{212} \mathrm{Bi}$. It should be noted that the proposed method of measuring the content of ${ }^{214} \mathrm{Bi},{ }^{214} \mathrm{~Pb}$ or ${ }^{212} \mathrm{~Pb},{ }^{212} \mathrm{Bi}$ can be used to estimate ${ }^{222} \mathrm{Ra}$ and ${ }^{220} \mathrm{Ra}$ in soil samples.

\section{Results and discussion}

The measurements were performed with the following goals: determining the activity concentration of natural/man-made radionuclides in soil probes from different depths $(0-50 \mathrm{~cm})$; investigating the radionuclides migration in depth; influence the soil actual acidity $\mathrm{pH}$ [12] on the contents and the migration of nuclides; radionuclides distribution along the mountain ridges and statistical correlation between the content of radionuclides, soil $\mathrm{pH}$ and sampling points. This also allows us to make an estimation of the radon content in near-surface layers of ground.

Taking into account that sampling was carried out in the mountains on different altitude, soil composition, average humidity and forest range, the instrumental methods should be complemented by statistical ones. It should be mentioned that uncorrected sampling procedures can give the error that exceed the measurement error. We used the following notation: $i$ - sampling point number of the protected areas, $n$-depth number $(n=1,2,3$, that corresponds to: surface -1 , middle depth -2 , and bottom depth of soil - 3), and A - marker-isotope in soil probe.

First of all, we calculated the activity concentration $c_{i, n}(\mathrm{~A})$ in $[\mathrm{Bq} / \mathrm{kg}]$ for sampling point at coordinate $(i, n)$, then $c_{\mathrm{A}}(n)-c_{\mathrm{A}}$ values, averaged over all $i$-samples taken to depth $n$ by an expression:

$$
c_{\mathrm{A}}(n)=\frac{1}{N} \sum_{i=1}^{N} c_{i, n}(\mathrm{~A})
$$

and finally $c_{\mathrm{A}}$, obtained by averaging over all samples:

$$
c_{\mathrm{A}}=\frac{1}{3} \sum_{n=1}^{3} c_{\mathrm{A}}(n)
$$

We also calculated their statistical correlations as $r_{\mathrm{A}, \mathrm{pH}}-$ Pearson's coefficient for $\left\{\mathrm{A}_{i}\right\}$ and $\left\{\mathrm{pH}_{i}\right\}$ arrays and correlation analysis (CA) to group the soil probes in concordance with their similarities and differences as resulting from the experimental activity concentrations of $\mathrm{A}$ radionuclides. The results of these investigations showed an absence of fundamental abnormality in investigated isotopes $\mathrm{A}={ }^{40} \mathrm{~K},{ }^{137} \mathrm{Cs}$, ${ }^{212} \mathrm{~Pb},{ }^{214} \mathrm{Bi}$ and acidity of soil $\mathrm{pH}$. Particularly, average values of $c_{\mathrm{A}}(n)$ for surface samples (for $n=1$ ) are equal to: for protected area Zacharovanyy Kray (hereinafter - ZachKr) for ${ }^{40} \mathrm{~K}-250 \mathrm{~Bq} / \mathrm{kg} ;{ }^{137} \mathrm{Cs}-$ $21 \mathrm{~Bq} / \mathrm{kg}$; and $\mathrm{pH}=4.4$. Average values of the deepest samples $(n=3)$ are equal to: for ${ }^{40} \mathrm{~K}-248.1 \mathrm{~Bq} / \mathrm{kg}$; ${ }^{137} \mathrm{Cs}-3.8 \mathrm{~Bq} / \mathrm{kg}$ and $\mathrm{pH}-3.8$. Surface samples for protected area Chorne Bahno (hereinafter - ChBhn) are: for ${ }^{40} \mathrm{~K}-271 \mathrm{~Bq} / \mathrm{kg} ;{ }^{137} \mathrm{Cs}-9.5 \mathrm{~Bq} / \mathrm{kg} ; \mathrm{pH}=4.4$. Average values of the deepest samples, respectively, are equal: for ${ }^{40} \mathrm{~K}-284.2 \mathrm{~Bq} / \mathrm{kg}$; ${ }^{137} \mathrm{Cs}-4.3 \mathrm{~Bq} / \mathrm{kg}$; $\mathrm{pH}=4.0$. Finally, surface samples for Ichthyological Preserve Rika (hereinafter - IchPrR) give for ${ }^{40} \mathrm{~K}=$ $370 \mathrm{~Bq} / \mathrm{kg} ;{ }^{137} \mathrm{Cs}-17.1 \mathrm{~Bq} / \mathrm{kg} ; \mathrm{pH}=4.2$. Average values of the deepest samples, respectively, changed: for ${ }^{40} \mathrm{~K}-398.3 \mathrm{~Bq} / \mathrm{kg} ;{ }^{137} \mathrm{Cs}-3.9 \mathrm{~Bq} / \mathrm{kg}$ and $\mathrm{pH}=$ 3.6. Finally, for Uzhanskij NP only surface soil probes $(n=1)$ were taken. The same values were: for ${ }^{40} \mathrm{~K}-$ $554.6 \mathrm{~Bq} / \mathrm{kg} ;{ }^{137} \mathrm{Cs}-16.2 \mathrm{~Bq} / \mathrm{kg} ; \mathrm{pH}=4.02$.

In Fig. 1, the investigated isotope content distribution with depth is presented. Here, $r(n)$ is the activity concentration ratio $c_{214 \mathrm{Bi}} / c_{212 \mathrm{~Pb}}$ measured as a function of depth. One can see the opposite trends for these dependences between changes of values and depth of sampling: growth of equivalent U series content (Fig. 1a) and a substantial decrease of technogenic ${ }^{137} \mathrm{Cs}$ content (Fig. 1b). 
a



b

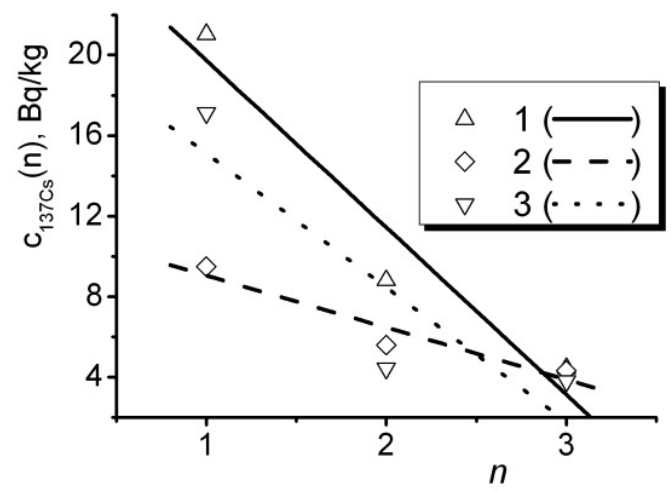

Fig. 1. The depth distribution of: (a) reduced U/Th content parameter $r$ (see in the text) and (b) ${ }^{137}$ Cs activity concentration. Here 1 - ZachKr, 2 - ChBhn, 3 - IchPrR.

Table 1. The statistical relationships between $\mathrm{pH}$ of soil probes and averaged activity concentrations $c(\mathrm{~A})$ for A isotopes for different protected areas

\begin{tabular}{lccc}
\hline \multicolumn{1}{c}{$\mathrm{A}$} & ZachKr & ChBhn & IchPrR \\
\hline${ }^{40} \mathrm{~K}$ & -0.25 & -0.37 & -0.37 \\
${ }^{214} \mathrm{Bi}$ & -0.20 & -0.27 & -0.38 \\
${ }^{212} \mathrm{~Pb}$ & 0.16 & 0.21 & 0.12 \\
${ }^{137} \mathrm{Cs}$ & 0.67 & 0.67 & 0.44 \\
\hline
\end{tabular}

The origin of these dependences lies in the solubility of the chemical forms in which each radionuclide is present. Assuming that uranium isotopes are the most mobile radionuclides [13], the much higher uranium concentrations in soils probe for the deeper horizons of sampling points most probably indicate that the major supply in this point is in a soluble form and is performed by the rains. This feature is common in all protected areas.

In Table 1, the Pearson's coefficients $r_{\mathrm{A}, \mathrm{pH}}$ between the soil's $\mathrm{pH}$ and averaged activity concentration for marker-isotopes A for all protected areas are presented. One can note the negative sign of the correlation coefficients for ${ }^{40} \mathrm{~K},{ }^{214} \mathrm{Bi}$ (uranium series), ${ }^{212} \mathrm{Bi}$ (thorium series) and significant values for ${ }^{137} \mathrm{Cs}$ correlation coefficient, which agrees with the data of Fig. 1.

It should be noted that those relationships are broken in the case of the data from Uzhanskij NP, where only surface soil probes were taken.

These data allow investigating the statistical dependences between the sampling points along the mountain ridges, slopes and valleys, and checking their homogeneity. In performing such analyses, we have used $c_{\mathrm{A}}$ as a multivariate parameter. According to the theory $[14,15]$ we considered each soil probe as a multidimensional function of A radionuclide activity concentration, and $c_{\mathrm{A}}$ is used to group the soil sampling points in concordance with their similarities and differences resulting from the experimental concentrations. The abilities of such calculation are demonstrated on example of ZachKr, where seven sampling points along the mountain ridges and in nearby valleys were chosen (Fig. 2a), [16, 17]. The analysis shows that the same regularities are common for other investigated protected areas, where soil samples were taken from deep (except Uzhanskij NP). It should be noted the constancy of statistical regularities for deep sampling points horizons $(n=$ 2 and 3$)$, whereas the surface samples $(n=1)$ do not show such dependence.

The tree diagrams related to $c_{\mathrm{A}}$ between $\mathrm{ZachKr}$ sample points on the base of ${ }^{40} \mathrm{~K},{ }^{137} \mathrm{Cs},{ }^{214} \mathrm{Bi}$ and ${ }^{212} \mathrm{~Pb}$ isotopes and for depth $n=2$ are shown in Fig. 2b. Calculations were performed by using the STATISTICA 9.0 software package. One can see a stronger correlation (little linkage distance) between sampling points on a ridge and the neighbouring and

a
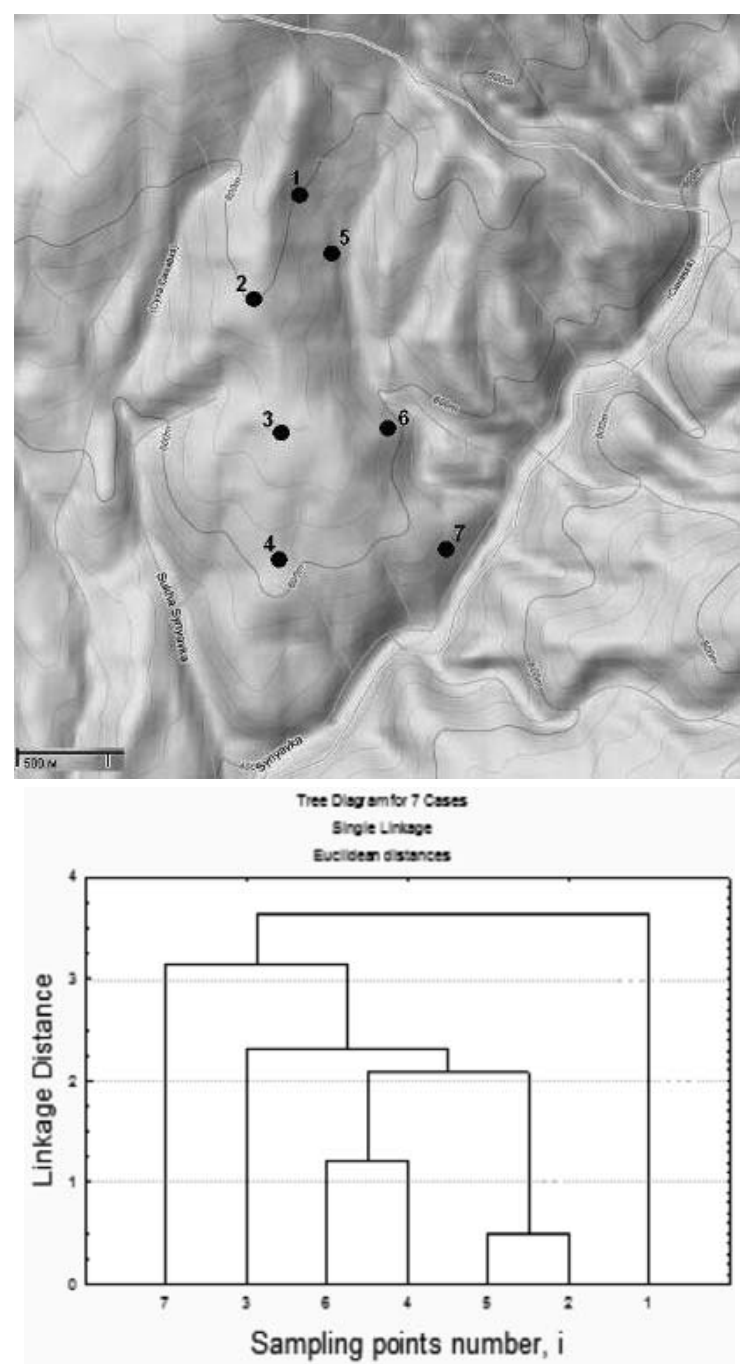

Fig. 2. The sampling scheme for ZachKr mountainous relief (a) and $c_{\mathrm{A}}$ diagrams for ZachKr sampling points (b). 
lower points in the valleys $(2-5,4-6)$, whereas such correlation for sampling points along mountain ridges (1-2-3-4) it is much smaller. This can be caused by the fact that chemical and microelements compositions for deep soil horizons are more stable and are formed by both chemical migration processes: along the slopes of the mountains and vertically to a soil depth, for example, under the influence of rains. The microelement composition of the grounds (surface soils), especially along the mountain ridges, is formed by more dynamical factors like winds.

To solve the main task, i.e. determination of the distribution of near-surface radon basing on the measurement of the amount of the elements of $U$ and $\mathrm{Th}$ radioactive series in the soil probes, very important is the preparation of the specimens for measurements, which should provide radioactive equilibrium between radionuclides neighbouring in these radioactive series.

For example, in the works $[18,19]$ the mentioned ${ }^{214} \mathrm{~Pb}$ element, produced at radioactive decay of ${ }^{226} \mathrm{Ra}$, was used to quantitate ${ }^{226} \mathrm{Ra}$. Another ${ }^{226} \mathrm{Ra}$ daughter, ${ }^{214} \mathrm{Bi}$, also was used to quantitate ${ }^{226} \mathrm{Ra}$. The main condition for correctness of these estimations was hermetization of the samples during 21 days that approximately is equal to six half-lives of the ${ }^{226} \mathrm{Ra}$ daughter, ${ }^{222} \mathrm{Rn}$. The secondary equilibrium for this was established before it is established for ${ }^{214} \mathrm{~Pb}$ and ${ }^{214} \mathrm{Bi}$, which have shorter half-lives. The author noticed that measurement of ${ }^{214} \mathrm{~Pb}$ or ${ }^{214} \mathrm{Bi}$ is more favourable than direct ${ }^{226} \mathrm{Ra}$ determination. Let's mention also the works $[20,21]$, where also was claimed about the possibilities of similar estimations. From these reasons, we also choose 21 day as a time of the probe hermetization. This is a period long enough for determining the content of long-living isotope ${ }^{226} \mathrm{Ra}$, and his daughter's component ${ }^{222} \mathrm{Rn}$, but is longer than the time needed for establishing an equilibrium for short-living elements, ${ }^{214} \mathrm{~Pb}$, or ${ }^{214} \mathrm{Bi}$, that consist about 2.5 hours.

The first results of radioactive mapping of the protected area of Transcarpathia of the ${ }^{214} \mathrm{Bi}$ content as marker of ${ }^{222} \mathrm{Rn}$ in humus soil profiles in the national parks 'Synevir' and 'Zacharovanyy Kray' are presented in Fig. 3.

From the above, it can be concluded that bigger near-surface concentrations of the ${ }^{214} \mathrm{~Pb}$ isotope provide information about increased content of ${ }^{222} \mathrm{Rn}$. This is possibly because ${ }^{214} \mathrm{~Pb}$, being the daughter isotope of ${ }^{222} \mathrm{Rn}$, comes to radioactive equilibrium after $0.5-1$ hour [22]. It is seen the considerable differences (up to $30 \%$ ) of the specific concentrations of ${ }^{214} \mathrm{Bi}$, which can reflect the variations of the near-surface radon content. As mentioned above, in consequence of enhanced movability of the isotopes of $U$ series, their concentration increases for the deeper horizons of sampling points, as well as for low-land territories of the mountain regions of the Carpathians. Such a tendency can cause changes of the isotope content of near-surface radon, for example, increasing the ${ }^{222} \mathrm{Rn}$ concentration for low-land areas of mountain regions, and enhancing the content of ${ }^{220} \mathrm{Rn}$ for high-land sites [6].
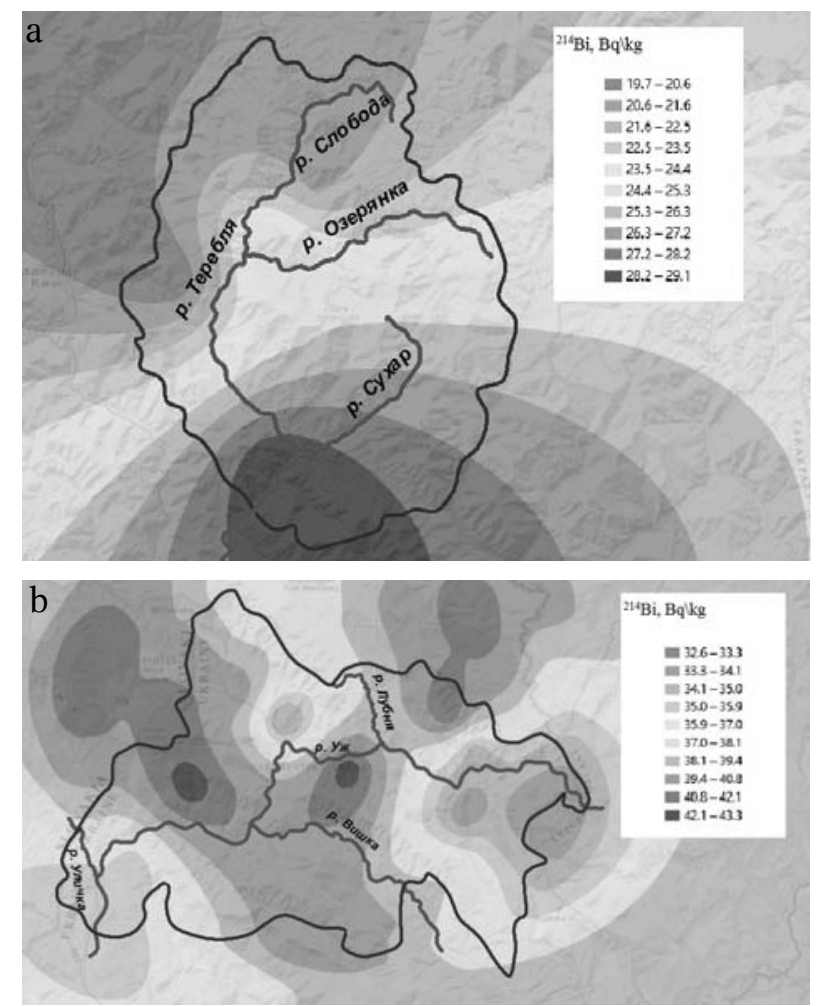

Fig. 3. The map of distribution of the total specific activity of the ${ }^{214} \mathrm{Bi}$ isotope in the humus soil profile in the protected areas: (a) Synevir, (b) ZachKr.

\section{Conclusions}

As follows from the above, the low-background gamma spectroscopy is a very useful method for environmental motoring and studies, and radionuclides are the effective 'marks' of ecological and geochemical condition of the Transcarpathian mountain region. Statistical analysis can be effectively used for estimating the reliability of sampling scheme and determination even weak similarities between sampling points. The obtained results demonstrate the statistical regularities between the natural and man-made radionuclides content, as well as with physical and chemical properties for soil samples from protected areas.

This method also is applicable for the evaluation of radon content, as well as for ${ }^{222} \mathrm{Rn}$ and ${ }^{220} \mathrm{Rn}$, for the both low-land and high-land areas in the Carpathians. Such data can be complementary to the independent measurements of the near-surface radon content, for example, by means of the instantaneous measurement methods, such as a double filter method, scintillation method, balloon method and activated charcoal method. In this case one can establish the numerical dependences between the contents of the isotopes-markers, like ${ }^{214} \mathrm{~Pb}$ or ${ }^{214} \mathrm{Bi}$, in the surface layers, and the radon concentration. These data are important for evaluating the radionuclide's standards in soils of the protected areas.

\section{References}

1. Hrabovskyy, V., Dzendzelyuk, O., Katerynchuk, I., \& Furgala, Yu. (2004). Monitoring of radionuclides 
contamination of soils in Shatsk National Natural Park (Volyn region, Ukraine) during 1994-2001. J. Environ. Radioact., 72(1), 25-33.

2. Kubica, B., Mietelski, J. W., Gołaś, J., Skiba, S., Tomankiewicz, E., Gaca, P., Jasińska, M., \& Tuteja-Krysa, M. (2002). Concentration of ${ }^{137} \mathrm{Cs},{ }^{40} \mathrm{~K},{ }^{238} \mathrm{Pu}$ and ${ }^{239+240} \mathrm{Pu}$ radionuclides. Pol. J. Environ. Studies, 11(5), 537-545.

3. Cochran, J. K., Feng, H., Amiel, D., \& Beck, A. (2006). Natural radionuclides as tracers of coastal biogeochemical processes. J. Geochem. Explor., 88(1/3), 376-379.

4. Pourcelot, D., Louvat, F., Gauthier-Lafaye, S., \& Stille, P. (2003). Formation of radioactivity enriched soils in mountain areas. J. Environ. Radioact., 68(3), 215-233.

5. Maňkovska, B., Oszlanyi, J., \& Barančok, P. (2008). Measurement of the atmosphere loading of the Slovak Carpathians using bryophyte technique. Ekologia (Bratislava), 27(4), 339-350.

6. Maslyuk, V. T., Svatyuk, N. I., Stets, M. V., Frontasyeva, M. V., \& Parlag, O. O. (2013). Statistical regularities in the distribution of radionuclides in sediments of Transcarpathia mountain rivers. J. Environ. Radioact., 117, 9-12. DOI: 10.1016/j.jenvrad.2012.04.016.

7. Symader, W., \& Roth, M. (2002). Changes in chemical characteristics of river bed samples caused by exceptional high floods in the Kartelbornsbach basin near Trier (pp. 333-338). International Association of Hydrological Sciences. (PIAHS vol. 276).

8. Bourdon, B., Turner, S., Henderson, G. M., \& Lundstrom, C. C. (2003). Introduction to U-series geochemistry. Rev. Mineral. Geochem., 52(1), 1-21.

9. Dragović, S., Mihailović, N., \& Gajić, B. (2008). Heavy metals in soils: distribution, relationship with soil characteristics and radionuclides and multivariate assessment of contamination sources. Chemosphere, 72(3), 491-495.

10. Krmar, M., Slivka, J., Varga, E., Bikit, I., \& Vesković, M. (2009). Correlations of natural radionuclides in sediment from Danube. J. Geochem. Explor., $100(1)$, 20-24.

11. Chen, J. M., Wasserburg, G. J., \& Edwards, R. L. (1992). Mass spectrometry and application to uranium-series disequilibrium. In $\mathrm{M}$. Ivanovich, \& $\mathrm{R}$. S. Harmon (Eds.), Uranium-series disequilibrium.
Applications to Earth, marine, and environmental sciences (2nd ed.) (pp. 174-206). Oxford: Clarendon Press.

12. McElnea, A. E., Ahern, C. R., \& Menzies, N. W. (2002). The measurement of actual acidity in acid sulfate soils and the determination of sulfidic acidity in suspension after peroxide oxidation. Soil Res., 40(7), 1133-1157.

13. Sheppard, S. C., Evenden, W. G., \& Anderson, A. J. (1992). Multiple assays of uranium toxicity in soil. Environ. Toxicol. Water Quality, 7(3), 275-294.

14. Davis, J. C., \& Sampson, R. J. (1986). Statistics and data analysis in geology (Vol. 646). New York: Wiley.

15. Yu, K. C., Tsai, L. J., Chen, S. H., \& Ho, S. T. (2001). Correlation analyses on binding behavior of heavy metals with sediment matrices. Water Res., 35(10), 2417-2428.

16. Yankovoi, A. G. (2001). Multivariate analysis in the system STATISTICA (pp. 1-216). Odessa: Optimum.

17. Sokal, R. R. (1958). A statistical method for evaluating systematic relationships. Univ. Kansas Sci. Bull., 38, 1409-1438.

18. Manolopoulou, M., Mironaki, D., \& Papastefanou, C. (2003). A new technique for the accurate measurement of ${ }^{226} \mathrm{Ra}$ by gamma spectroscopy in voluminous samples. Nucl. Instrum. Methods Phys. Res. Sect. A-Accel. Spectrom. Dect. Assoc. Equip., 508(3), 362-366.

19. Stoate, L. (2012). Determination of levels of background radiation in soils samples. Doctoral dissertation, University of Surrey, UK.

20. Tucker, B., Donakowski, J., \& Hays, D. (2012). Comparison of activity determination of radium 226 in FUSRAP soil using various energy lines - 12299. In Proceedings WM-2012 Conference, 26 February - 1 March, 2012 (pp. 1-9). Phoenix, Arizona, USA.

21. Chabot, G. (2008). Answer to Question \#7823 Submitted to "Ask the Experts", Health Physics Society, Surveys and Measurements (SM). Retrieved October 1, 2008, from https://hps.org/publicinformation/ate/ q7823.html.

22. Lozano, J. C., Blanco, P. R., \& Vera Tome, F. (2002). Distribution of long-lived radionuclides of the ${ }^{238} \mathrm{U}$ series in the sediments of a small river in a uranium mineralized region of Spain. J. Environ. Radioact., 63(2), 153-171. 